\title{
USO DO ADESIVO ETIL-CIANOACRILATO EM DERMORRAFIAS DE OVINOS
}

\author{
ETHYL-CYANOACRYLATE ADHESIVE IN SKIN SUTURES IN SHEEP
}

\author{
P. V. T. MARINHO ${ }^{1 *}$, P. I. NÓBREGA NETO ${ }^{2}$, C. M. B. A. SILVA ${ }^{2}$, J. A. BATISTA ${ }^{2}$, \\ G. J. N. GALIZA ${ }^{3}$, A. F. M. DANTAS ${ }^{2}$, B. W. MINTO ${ }^{4}$
}

\begin{abstract}
RESUMO
Para avaliar e comparar clínica e histologicamente o uso do adesivo etil-cianoacrilato na reparação de feridas cirúrgicas de pele foram utilizados sete ovinos adultos, clinicamente sadios. Os animais foram sedados e anestesiados e realizaram-se duas incisões de cinco centímetros na pele, uma em cada fossa paralombar. A dermorrafia foi realizada com fio de náilon monofilamentar número 0, em padrão simples separado (grupo controle) ou com o adesivo de etilcianoacrilato (grupo tratamento). As feridas cutâneas foram avaliadas diariamente até o $10^{\circ}$ dia pós-operatório quanto ao edema, secreção e deiscência. Para avaliação histológica do processo cicatricial, foram realizadas biopsias de ambas as feridas experimentais aos 10, 20 e 30 dias após a cirurgia. O procedimento cirúrgico durou em média 16,2士1,92 minutos no grupo controle e 11,2 $\pm 2,58$ minutos no grupo tratamento e ambos os grupos induziram bons processos cicatriciais tanto macroscopicamente como histologicamente. Os resultados obtidos permitem concluir que o adesivo de etil-cianoacrilato possui boa adesividade e quando empregado na síntese de feridas cutâneas na região avaliada em ovinos, reduziu o tempo de realização do procedimento cirúrgico em 30,9\%, não interferindo com o processo cicatricial e propiciando excelente resultado estético, sem necessidade de remoção dos pontos.
\end{abstract}

PALAVRAS-CHAVE: Adesivo cutâneo. Cicatrização. Pele. Sutura.

\section{SUMMARY}

To evaluate and compare clinically and histologically the use of the ethyl-cyanoacrylate adhesive on repairing of skin surgical wounds, were used 7 adult sheep, clinically healthy. The animals were anaesthetized and two incisions of $5 \mathrm{~cm}$ on the skin were made. The skin suture was made with nylon 0, in simple separate pattern (control group) or with ethylcyanoacrylate adhesive (group treatment). The skin wounds were daily assessed until the $10^{\text {th }}$ day post-operative regarding edema, secretion and dehiscence. For histological evaluation of the process, took place biopsy of both experimental wounds to 10, 20 and 30 days after surgery. The surgical procedure lasted on average $16.2 \pm 1.92$ minutes in the control group and $11.2 \pm 2.58$ minutes in the treatment group and both groups induced good healing process both macroscopically and histologically. The results showed that the ethyl-cyanoacrylate adhesive has good adhesion, and when employed in the synthesis of skin wounds in sheep, reduced the time of realization of the surgical procedure in $30.9 \%$, not interfering with the scarring procedure and providing excellent aesthetic results without the need for removal the points.

KEY-WORDS: Cutaneous adhesive. Scarring. Skin. Suture.

\footnotetext{
${ }^{1}$ Universidade Estadual de Londrina. Email.: paulo.veter@gmail.com

${ }^{2}$ Universidade Federal de Campina Grande

${ }^{3}$ Universidade Federal de Santa Maria

${ }^{4}$ Universidade Estadual Paulista "Júlio de Mesquita Filho", Campus Jaboticabal, SP
} 


\section{INTRODUÇÃO}

A síntese dos tecidos tem por objetivo mantêlos bem coaptados, o que acelera o processo de cicatrização, previne hemorragias pós-operatórias e contribui para a formação e manutenção do coágulo sanguíneo, evitando a infecção, diminuindo a dor pósoperatória e a penetração de corpos estranhos na ferida (EDWAB, 1995).

Os adesivos teciduais constituem um grupo de biomateriais definidos como substâncias polimerizáveis, através das quais se busca manter os tecidos unidos ou a promoção de barreira contra extravasamentos (REECE et al., 2001).

Os cianoacrilatos são monômeros monofuncionais puros, cujas bases são ésteres do ácido cianoacrílico com uma cadeia alquil lateral (WATTÉ et al., 2004; KIM et al., 2013). Quando um iniciador de uma reação de polimerização é acrescentado ao monômero, a polimerização ocorre imediatamente (KIM et al., 2013). Essa velocidade de adesão torna mais rápido o procedimento cirúrgico, dando mais segurança à intervenção emergencial (FOSSUM, 2002).

Apesar das várias vantagens dos cianoacrilatos sobre a sutura convencional, os mesmos podem ser histotóxicos (BAPTISTA, 1995; DE MELO et al., 2013). A toxicidade dos adesivos está relacionada com a sua velocidade de degradação e esta, com o tamanho da cadeia lateral, ou seja, quanto maior for a cadeia, menor a velocidade de degradação e menor a histotoxicidade (SASKA et al., 2004). Segundo Shermak et al. (1998), essa toxicidade também deve-se à ionização dos adesivos à base de cianoacrilato, que, na presença de água ou sangue, degradar-se-iam para formar cianoacetato e formaldeído, com ligeira reação exotérmica. Com o objetivo de reduzir a toxicidade, foram promovidas diversas alterações na composição do cianoacrilato, substituindo-se o radical metil por etil, butil, hexil até dexil (FISCH, 1962). Porém, estas alterações de grupamento fizeram diminuir a adesividade, já que quanto maior a cadeia lateral, menor a adesividade. No entanto, isto trouxe vantagens como menor intensidade da reação exotérmica e, consequentemente, menor lesão tecidual e toxicidade (PAPATHEOFANIS \& BARMADA, 1993).

Objetivou-se com este experimento analisar de forma comparativa a duração da cirurgia e a evolução macro e microscópica do processo cicatricial de feridas cutâneas experimentais de ovinos suturadas com fio de náilon ou com um adesivo de etil-cianoacrilato.

\section{MATERIAL E MÉTODOS}

Foram utilizados sete ovinos adultos, sem raça definida, clinicamente sadios, com peso de $20,5 \pm 2,7 \mathrm{~kg}$ (média \pm desvio padrão). Os animais foram mantidos em um curral coletivo, sendo alimentados com feno de capim tifton (Cynodon dactylon) e água ad libitum, além de concentrado à base de farelo de milho (100 g/animal/dia).

Foram compostos dois grupos experimentais, representados por cada uma das fossas paralombares (direita e esquerda) de cada animal, onde um foi constituído pelas feridas cutâneas suturadas com fio náilon (grupo controle) e o outro formado pelas dermorrafias realizadas com o adesivo de etilcianoacrilato $^{5}$ (grupo tratamento). A escolha de qual fossa paralombar recebeu o fio ou adesivo foi realizada ao acaso no primeiro animal operado, e em todos os outros se alternou continuamente.

A pesquisa desenvolvida foi previamente aprovada pelo Comitê de Ética em Pesquisa (CEP), sob protocolo de número 128/2009.

Para o procedimento experimental, os animais foram submetidos a um jejum alimentar por 12 horas, após o que foram pesados e, após a mensuração dos parâmetros basais a serem avaliados, foram sedados com cloridrato de xilazina ${ }^{6}$, na dose de $0,2 \mathrm{mg} / \mathrm{kg}$, pela via intramuscular.

Cinco minutos após a administração do cloridrato de xilazina, realizou-se tricotomia de cerca de 15 x 15 centímetros na região da fossa paralombar direita e esquerda, cerca de cinco centímetros ventralmente às apófises transversas das vértebras lombares e cinco centímetros caudalmente à última costela.

Após a anestesia e tricotomia, o animal foi contido e posicionado em decúbito lateral, sobre a mesa cirúrgica.

Em seguida foi realizada a anestesia local infiltrativa subcutânea no local da incisão, com lidocaína $1 \% \quad\left(5 \mathrm{~mL}\right.$ de lidocaína $2 \%$ com vasoconstrictor ${ }^{7}$ adicionados de $5 \mathrm{~mL}$ de solução de $\mathrm{NaCl} 0,9 \%$ ), na dose de $10 \mathrm{ml}$ em cada flanco.

A anti-sepsia do campo operatório foi realizada com digluconato de clorexidina a $0,5 \%{ }^{8}$. Após a colocação do pano de campo fenestrado, o procedimento cirúrgico foi iniciado com a demarcação do tamanho da incisão (cinco centímetros), sendo esta realizada através de um paquímetro. A incisão foi feita no sentido dorso-ventral envolvendo apenas a pele e o subcutâneo, fazendo-se necessária a hemostasia por torção dos pequenos vasos. $\mathrm{Na}$ sequência, o espaço morto subcutâneo foi reduzido, com fio categute simples número 2-0 em padrão de sutura zigue-zague (MARQUES et al., 2013). A dermorrafia das feridas do grupo tratamento foi realizada com o adesivo de etilcianoacrilato (Figuras 1A) e no grupo controle com fio de náilon monofilamentar número 0 , em padrão simples separado (Figura 1B). No grupo controle foram realizados quatro pontos de sutura, distantes um centímetro um do outro. No grupo tratamento foram aplicadas quatro gotas do adesivo, também distanciadas um centímetro uma da outra e aplicadas em ponte, sobre os dois bordos da ferida, mantidos unidos por compressão digital durante 30 segundos após a aplicação do adesivo.

\footnotetext{
${ }^{5}$ Superbonder - Loctite do Brasil Ltda - São Paulo, SP.

${ }^{6}$ Xilazin $2 \%$ - Syntec do Brasil Ltda - Cotia, SP.

${ }^{7}$ Anestésico Bravet - Laboratórios Bravet Ltda - Rio de Janeiro, RJ.

${ }^{4}$ Riohex 0,5\% - Rio Química Indústria Farmacêutica - São José do Rio Preto, SP
} 


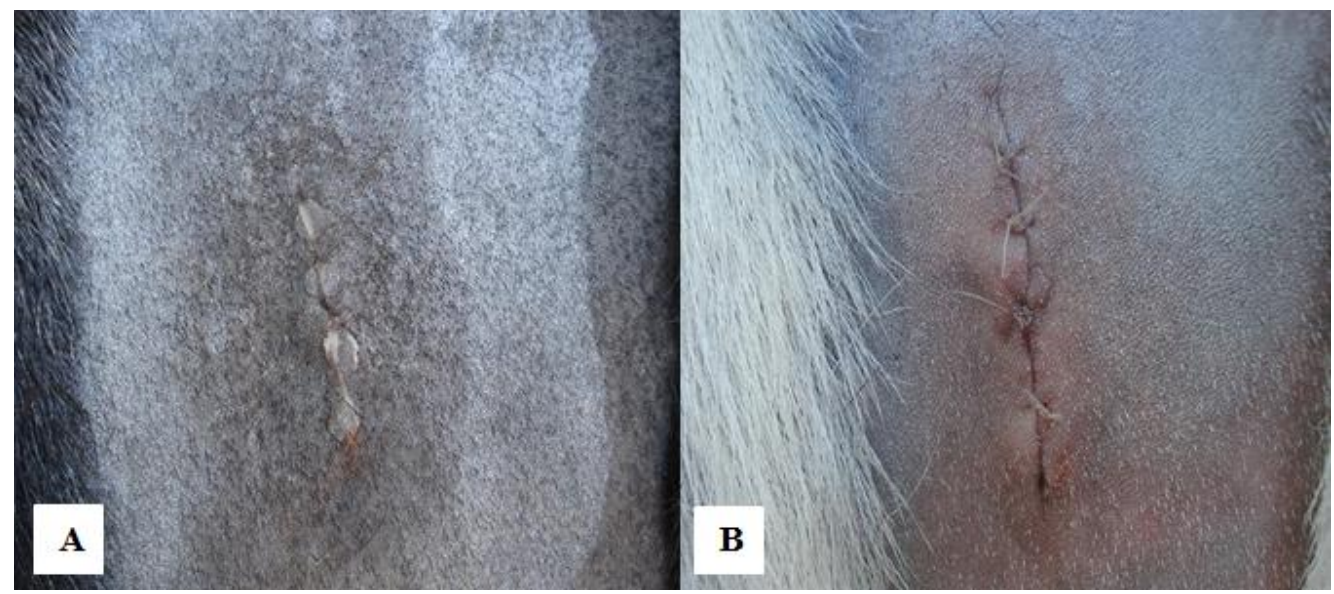

Figura 1- Imagem fotográfica com aspecto da ferida cirúrgica no $5^{\circ}$ dia pós-operatório em ovino submetido à dermorrafia com adesivo de etil-cianoacrilato (A) e fio de náilon (B)

Ao término do procedimento cirúrgico administrou-se flunixin meglumine ${ }^{9}$, na dose de 1 $\mathrm{mg} / \mathrm{kg}$, IM, o qual foi readministrado 24 e 48 horas após a primeira administração. Aplicou-se diariamente sulfadiazina tópica ${ }^{10}$ ao redor das feridas cutâneas sem contato com os seus bordos. As suturas do grupo controle foram removidas no décimo dia pós-operatório.

$\mathrm{O}$ tempo do procedimento cirúrgico foi mensurado, em ambos os grupos. As frequências respiratória e cardíaca, a temperatura corpórea e a motilidade ruminal foram mensuradas diariamente, sempre no mesmo horário, até o $10^{\circ}$ dia pós-operatório. A avaliação macroscópica das feridas foram realizadas diariamente até $\mathrm{o} 10^{\circ}$ dia pós-operatório quanto à hiperemia, edema e à presença de secreção e/ou deiscência. Esses parâmetros foram avaliados e em cada aspecto foram atribuídas notas de 0 a 3 , segundo a seguinte escala: 0 - ausência; 1 - leve; 2 - moderada e 3 - intensa.

Para avaliação histológica do processo cicatricial, foram realizadas biópsias de ambas as feridas experimentais (grupos controle e tratamento) 10,20 e 30 dias após a cirurgia. Previamente à realização da biópsia foi realizado bloqueio anestésico local, da mesma forma que o realizado para a cirurgia. Realizou-se tricotomia ao redor da ferida cirúrgica e antissepsia com Iodopovidona $10 \%$ e logo após procedeu-se a coleta do material, utilizando um punch de seis milímetros de diâmetro. Os fragmentos de pele foram conservados em formol a 10\%, fixados, clivados, diafanizados, embebidos em parafina e cortados em micrótomo, na espessura de quatro ou cinco micras. A seguir, as lâminas montadas foram coradas pela técnica de hematoxilina e eosina e analisadas em microscópico óptico. Cada fragmento foi avaliado em microscópio óptico quanto à presença de crostas, espessamento da epiderme, retração da epiderme, fibrose, inflamação e necrose. Em cada

\footnotetext{
${ }^{5}$ Banamine 5\% - Schering-Plough Veterinária Ltda - Cotia, SP.

${ }^{6}$ Bactrovet Spray Prata - Laboratórios König Ltda - João Pesso, PB.
}

aspecto foram atribuídas notas de 0 a 3 , seguindo a seguinte escala: 0 - ausência; 1 - pequena quantidade; 2 - quantidade moderada e 3 - grande quantidade.

A análise estatística foi realizada empregando o programa Graphpad Instat 3.0. Os parâmetros fisiológicos foram avaliados com o emprego da análise de variância para amostras repetidas e a comparação entre os momentos foi realizada pelo teste de StudentNewman-Keuls. Para avaliação da duração do procedimento cirúrgico, empregou-se o teste $t$ de Student para amostras independentes, com correção de Welch. Os achados histopatológicos foram avaliados pelo teste de Mann-Whitney. Ambos os testes foram aplicados ao nível de 5\% de significância.

\section{RESULTADOS E DISCUSSAO}

Observou-se redução significativa na duração do procedimento cirúrgico, o qual durou em média $16,2 \pm 1,92$ minutos no grupo controle e 11,2 $\pm 2,58$ minutos no grupo tratamento. Obteve-se, portanto, uma diferença de cinco minutos entre as médias dos grupos, o que equivale a $30,9 \%$ de redução na duração total do procedimento. Estes achados estão de acordo com Correia (2005) e Marques et al. (2013), os quais, trabalhando com caprinos e asininos, respectivamente, confirmaram a redução do tempo trans-operatório como um dos pontos mais positivos no emprego do adesivo de etil-cianoacrilato.

Hachida et al. (1997) também compararam o tempo gasto para ocluir o brônquio principal direito de 10 porcos, 5 com n-butil-cianoacrilato (grupo A) e 5 com sutura interrompida de ácido poliglicólico 3-0 (grupo B). O tempo requerido para a oclusão foi de 10 $\pm 3,6$ minutos para o grupo A e $25 \pm 6,5$ minutos para o grupo B, demostrando assim a agilidade conferida pelo uso do adesivo, confirmando os resultados obtidos no referido experimento.

A redução significativa obtida com o emprego do adesivo de etil-cianoacrilato pode justificar sua adoção na dermorrafia de diversos procedimentos, tendo em vista o fato de que a sutura convencional é muitas vezes laboriosa. Para Andrade et al. (2001), os 
adesivos cirúrgicos representam uma alternativa às suturas convencionais, apresentando vantagens como facilidade técnica e diminuição do tempo transcirúrgico, uma vez que reduzem o tempo despendido com a síntese, reduzindo, portanto o risco de contaminação, já que o órgão ou região anatômica submetida à cirurgia fica menos exposto ao ambiente, além de diminuir o período de recuperação da ferida cirúrgica, por facilitar a síntese tecidual.
Quanto aos parâmetros fisiológicos, não foram observadas variações em nenhum dos avaliados (Tabela 1) até o $10^{\circ}$ dia pós-operatório, os quais se mantiveram dentro dos limites fisiológicos para a espécie (FEITOSA, 2004), denotando que os procedimentos cirúrgicos não chegaram a alterar as funções orgânicas avaliadas. Resultado semelhante foi encontrado por Costa (2009) em bovinos.

Tabela 1 - Variação (média \pm desvio padrão) das frequências cardíaca (FC) e respiratória (FR), da temperatura corpórea (TC) e da motilidade ruminal (MR) de ovinos submetidos à dermorrafias com fio náilon e com adesivo de etil-cianoacrilato

\begin{tabular}{|c|c|c|c|c|c|c|c|c|c|c|c|}
\hline \multirow{2}{*}{$\begin{array}{l}\text { Parâ- } \\
\text { metro }\end{array}$} & \multirow{2}{*}{$\begin{array}{l}\text { Antes da } \\
\text { cirurgia }\end{array}$} & \multicolumn{10}{|c|}{ Dias após a cirurgia } \\
\hline & & 1 & 2 & 3 & 4 & 5 & 6 & 7 & 8 & 9 & 10 \\
\hline FC* & $\begin{array}{c}124,8 \pm \\
28,8\end{array}$ & $\begin{array}{c}94,1 \pm \\
22,5\end{array}$ & $\begin{array}{c}83,5 \pm \\
22,0\end{array}$ & $\begin{array}{c}100,6 \pm \\
16,8\end{array}$ & $\begin{array}{c}93,6 \pm \\
21,4\end{array}$ & $\begin{array}{c}70,4 \pm \\
10,8\end{array}$ & $\begin{array}{c}89,6 \pm \\
11,1\end{array}$ & $\begin{array}{c}94,4 \pm \\
20,1\end{array}$ & $\begin{array}{c}109,2 \pm \\
38,7\end{array}$ & $\begin{array}{c}112,4 \pm \\
29,1\end{array}$ & $\begin{array}{l}97 \pm \\
27,7\end{array}$ \\
\hline $\mathrm{FR}^{* *}$ & $\begin{array}{c}33,1 \pm \\
10,1\end{array}$ & $\begin{array}{c}42,3 \pm \\
15,3\end{array}$ & $\begin{array}{c}32,8 \pm \\
6,3\end{array}$ & $\begin{array}{c}28,3 \pm \\
6,9\end{array}$ & $\begin{array}{c}48,8 \pm \\
18,1\end{array}$ & $\begin{array}{c}27,8 \pm \\
3,8\end{array}$ & $\begin{array}{c}30,4 \pm \\
10,0\end{array}$ & $\begin{array}{c}32,0 \pm \\
4,8\end{array}$ & $\begin{array}{c}38,4 \pm \\
7,2\end{array}$ & $\begin{array}{c}30,0 \pm \\
9,1\end{array}$ & $\begin{array}{c}37,0 \pm \\
5,0\end{array}$ \\
\hline $\mathrm{TC}^{\#}$ & $\begin{array}{c}39,1 \pm \\
0,2\end{array}$ & $\begin{array}{c}39,4 \pm \\
0,1\end{array}$ & $\begin{array}{c}39,3 \pm \\
0,3\end{array}$ & $\begin{array}{c}39,3 \pm \\
0,6\end{array}$ & $\begin{array}{c}39,7 \pm \\
0,6\end{array}$ & $\begin{array}{c}38,6 \pm \\
0,4\end{array}$ & $\begin{array}{c}39,1 \pm \\
0,3\end{array}$ & $\begin{array}{c}39,1 \pm \\
0,3\end{array}$ & $\begin{array}{c}38,4 \pm \\
0,5\end{array}$ & $\begin{array}{c}38,1 \pm \\
0,5\end{array}$ & $\begin{array}{c}39,2 \pm \\
0,4\end{array}$ \\
\hline $\mathrm{MR}^{\# \#}$ & $\begin{array}{c}1,6 \pm \\
0,8\end{array}$ & $\begin{array}{c}1,6 \pm \\
0,8\end{array}$ & $\begin{array}{c}1,8 \pm \\
0,9\end{array}$ & $\begin{array}{c}1,6 \pm \\
1,0\end{array}$ & $\begin{array}{c}2,6 \pm \\
0,5\end{array}$ & $\begin{array}{c}2,2 \pm \\
0,4\end{array}$ & $\begin{array}{c}2,0 \pm \\
1,0\end{array}$ & $\begin{array}{c}1,8 \pm \\
0,8\end{array}$ & $\begin{array}{c}2,4 \pm \\
0,5\end{array}$ & $\begin{array}{c}2,0 \pm \\
0,7\end{array}$ & $\begin{array}{c}1,7 \pm \\
0,5\end{array}$ \\
\hline
\end{tabular}

*- expresso em bpm (batimentos por minuto)

**- expresso em mpm (movimentos por minuto)

\#- expresso em ${ }^{\circ} \mathrm{C}$ (graus centígrados)

\#\#- expresso em número de movimentos a cada 2 minutos

A avaliação dessas variáveis fisiológicas é de fundamental importância quando se deseja experimentar novas técnicas, principalmente quando relacionadas a procedimentos cirúrgicos, onde alterações nos mesmos podem ser indicativas de reações adversas decorrentes dos materiais, produtos ou da própria técnica cirúrgica.

A avaliação macroscópica diária do processo cicatricial das feridas cirúrgicas mostrou que ambas as técnicas induziram boa cicatrização e nenhuma ferida apresentou qualquer tipo de secreção. Hiperemia moderada foi observada em três animais no grupo controle até o quinto dia de pós-operatório, tornando-se leve na avaliação realizada no $10^{\circ}$ dia pós-operatório. Isso pode ser justificado pelo trauma adicional causado pela agulha no momento da sutura. Esses dados concordam com Vastani \& Maria (2013), que utilizaram cianoacrilato na mucosa oral e observaram que a incidência de hiperemia foi aumentada no lado suturada no primeiro, sétimo e décimo quarto dia de pós-operatório, mas foi semelhante ao do lado colado no vigésimo primeiro dia pós-operatório. Três animais apresentaram edema leve em ambos os grupos e um apenas no grupo tratamento. Em todos os casos, o edema perdurou apenas até o terceiro dia pós-cirúrgico. Este achado já era esperado, pois o edema é comum na fase inflamatória inicial da cicatrização, que dura em média de três a cinco dias (HESS, 2002).

A fim de evitar interferência da técnica operatória na adesividade do etil-cianoacrilato e consequente descência da ferida, hemostasia foi realizada de forma cuidadosa. Segundo Matera et al. (1999) e Mixter (1998), o controle do sangramento é importante durante a aplicação dos cianoacrilatos, uma vez que a presença de sangue afeta a sua capacidade adesiva.

A escolha de qual fossa paralombar recebeu o fio ou adesivo foi realizada ao acaso no primeiro animal operado, e em todos os outros se alternou continuamente o lado (direito ou esquerdo) a ser considerado controle ou tratamento, de modo que ambos os grupos foram equitativamente distribuídos entre ambas as fossas paralombares (direita e esquerda), vendo o fato que dois fatores poderiam interferir no processo cicatricial, e desta forma mascarar ou até mesmo tendenciar o resultado, sendo estes, a tensão exercida pelo rúmen no lado esquerdo e o maior contato da ferida do lado direito com o piso do curral, devido à maior frequência do decúbito esterno-abdominal direito adotado pelos ruminantes (OLIVEIRA, 1991).

Ocorreu deiscência de oito milímetros em um animal do grupo tratamento, possivelmente devido a uma má distribuição do adesivo cutâneo no momento da sua aplicação, o que impediu a coaptação perfeita dos bordos. Segundo Fossum (2002), a persistência da cola na derme pode resultar na formação de granuloma ou deiscência e sua colocação num local infectado pode associar-se com fistulação. Outro fator que pode ter contribuído para a deiscência foi o comportamento arisco dos animais, os quais quando na presença da equipe dentro do curral, se jogavam diretamente sobre a cerca, possibilitando a ocorrência de traumas à ferida cirúrgica. Costa (2009) observou o mesmo problema de deiscência na síntese cutânea com etil-cianoacrilato em dois dos seis bovinos que compunham o grupo experimental, justificado pela má distribuição do adesivo no momento da aplicação em um animal (deiscência de 
2,2 centímetros) e no outro (deiscência de 7,0 centímetros) pelo comportamento agressivo do mesmo ao ser contido, o qual se jogava violentamente ao solo, em decúbito lateral, causando traumas à ferida cirúrgica.

Quanto ao aspecto estético as feridas do grupo tratamento apresentaram-se com melhor qualidade em todos os animais (Figuras 2A e B), confirmando as citações de Borba et al. (2000) e Correia (2005), que utilizaram o cianoacrilato na síntese cutânea de ratos e de caprinos, respectivamente. Isso pode ser justificado pelo fato de o adesivo ser aplicado sobre os bordos da ferida, não causando traumatismo e agressão adjacente à incisão, nem necrose tecidual por tensão exagerada do fio, como muitas vezes observa-se na utilização do fio de sutura na dermorrafia.

$\mathrm{Na}$ análise histológica do processo cicatricial (Figuras 3 e 4) não foram observadas diferenças significativas entre os tratamentos quanto aos aspectos crosta, espessamento e retração da epiderme, fibrose e necrose (Tabela 2).

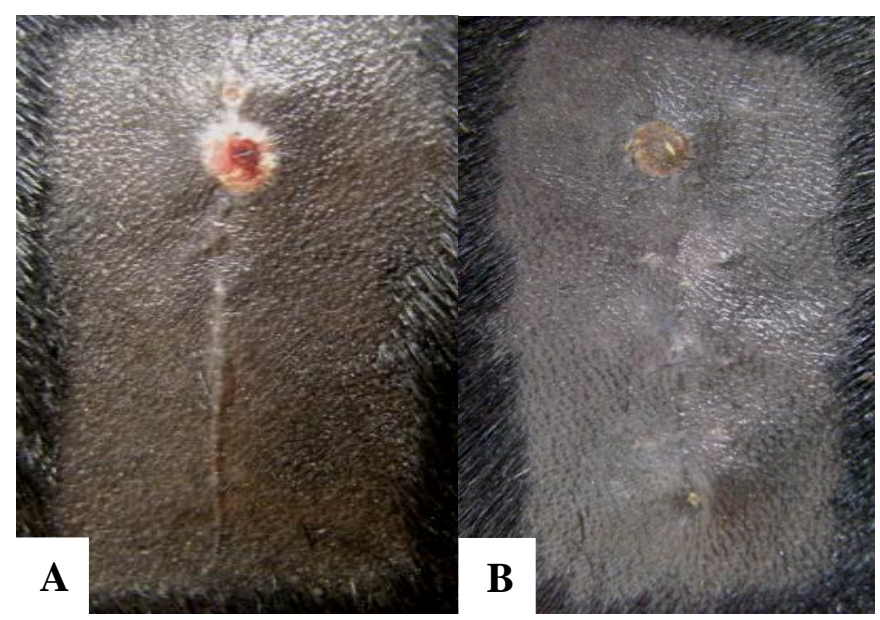

Figura 2 - Aspecto estético das feridas cirúrgicas no $20^{\circ}$ dia pós-operatório em ovino submetido à dermorrafia com adesivo de etil-cianoacrilato (A) e com fio náilon (B)

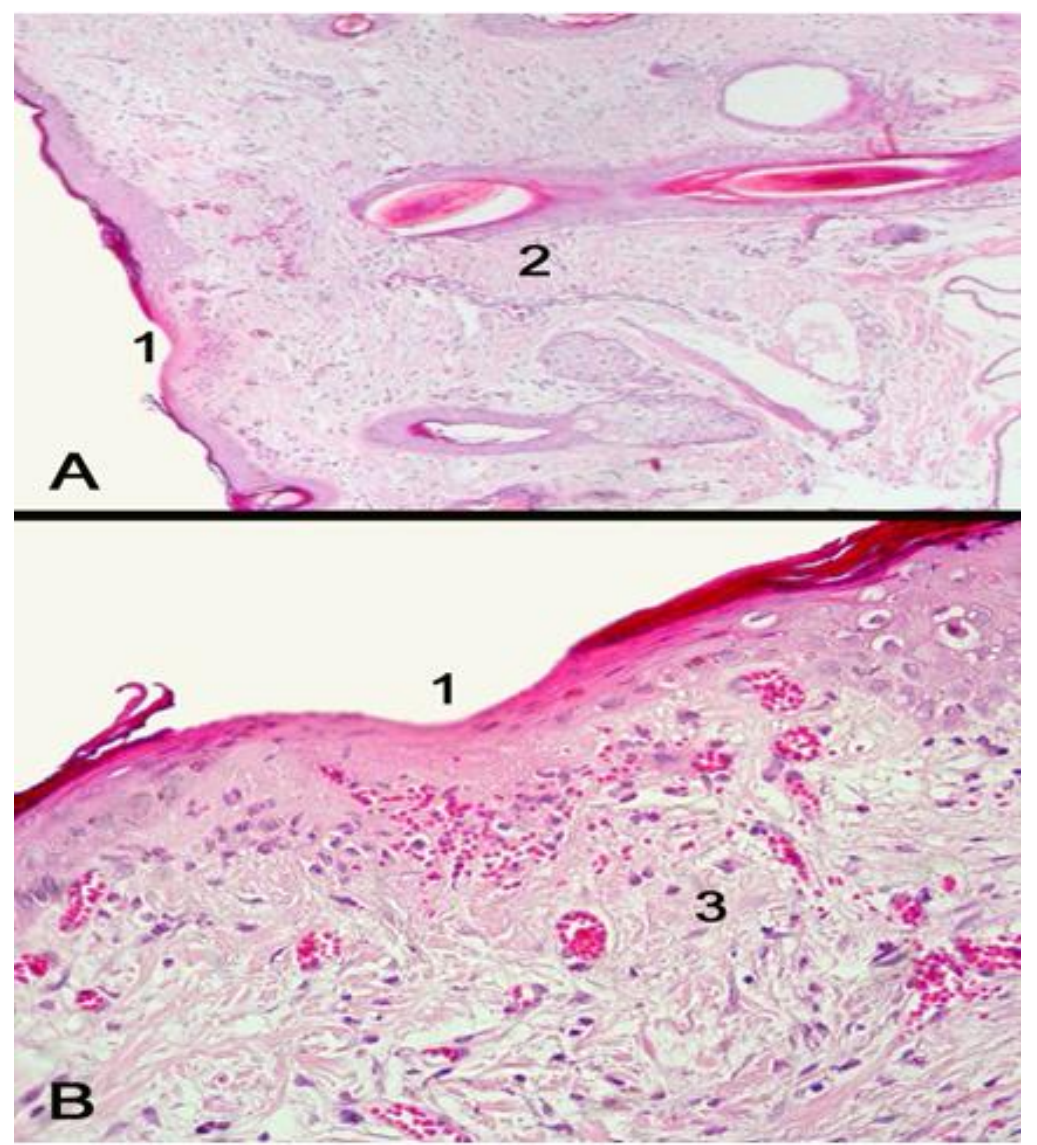

Figura 3 - Fotomicrografia de corte histológico de fragmento de pele de ovino submetido à dermorrafia com fio náilon (GC) no $10^{\circ}$ dia pós-operatório. A. Necrose discreta da epiderme (1), Inflamação (presença de neutrófilos) (2). B. Áreas de necrose em maior aumento (1), Inflamação (raros neutrófilos) e fibrose na derme superficial (3). A (HE - 4X). B (HE - 40X) 
Tabela 2 - Valores médios da avaliação histológica** de biópsias cutâneas realizadas em ovinos aos 10, 20, e 30 dias pós-operatórios (DPO), em dermorrafias realizadas com fio náilon (grupo controle - GC) ou com adesivo de etilcianoacrilato (grupo tratamento - GT

\begin{tabular}{cccccccc}
\hline \multirow{2}{*}{ DPO } & Grupo & \multicolumn{6}{c}{ Achados histológicos } \\
\cline { 3 - 8 } & Experimental & Crosta & $\begin{array}{c}\text { Retração da } \\
\text { Epiderme }\end{array}$ & $\begin{array}{c}\text { Espessamento da } \\
\text { Epiderme }\end{array}$ & Fibrose & Inflamação & Necrose \\
\hline \multirow{2}{*}{$10^{\circ}$} & GC & 0,4 & 1,4 & 1,4 & 1,0 & 1,2 & 0,6 \\
& GT & 0,0 & 1,0 & 1,8 & 1,4 & $2,8^{\#}$ & 0,6 \\
$20^{\circ}$ & GC & 0,0 & 1,0 & 1,0 & 1,2 & 1,4 & 0,0 \\
& GT & 0,0 & 1,0 & 1,2 & 1,6 & $1,2 *$ & 0,0 \\
$30^{\circ}$ & GC & 0,0 & 0,6 & 0,8 & 1,2 & 1,2 & 0,2 \\
& GT & 0,0 & 1,0 & 0,6 & 1,6 & $1,6^{*}$ & 0,0 \\
\hline
\end{tabular}

** Graus: Ausência=0; Pequena quantidade=1; Quantidade moderada=2; Grande quantidade=3

* - significativamente diferente do $10^{\circ}$ dia pós-cirúrgico

\# - significativamente diferente do grupo controle

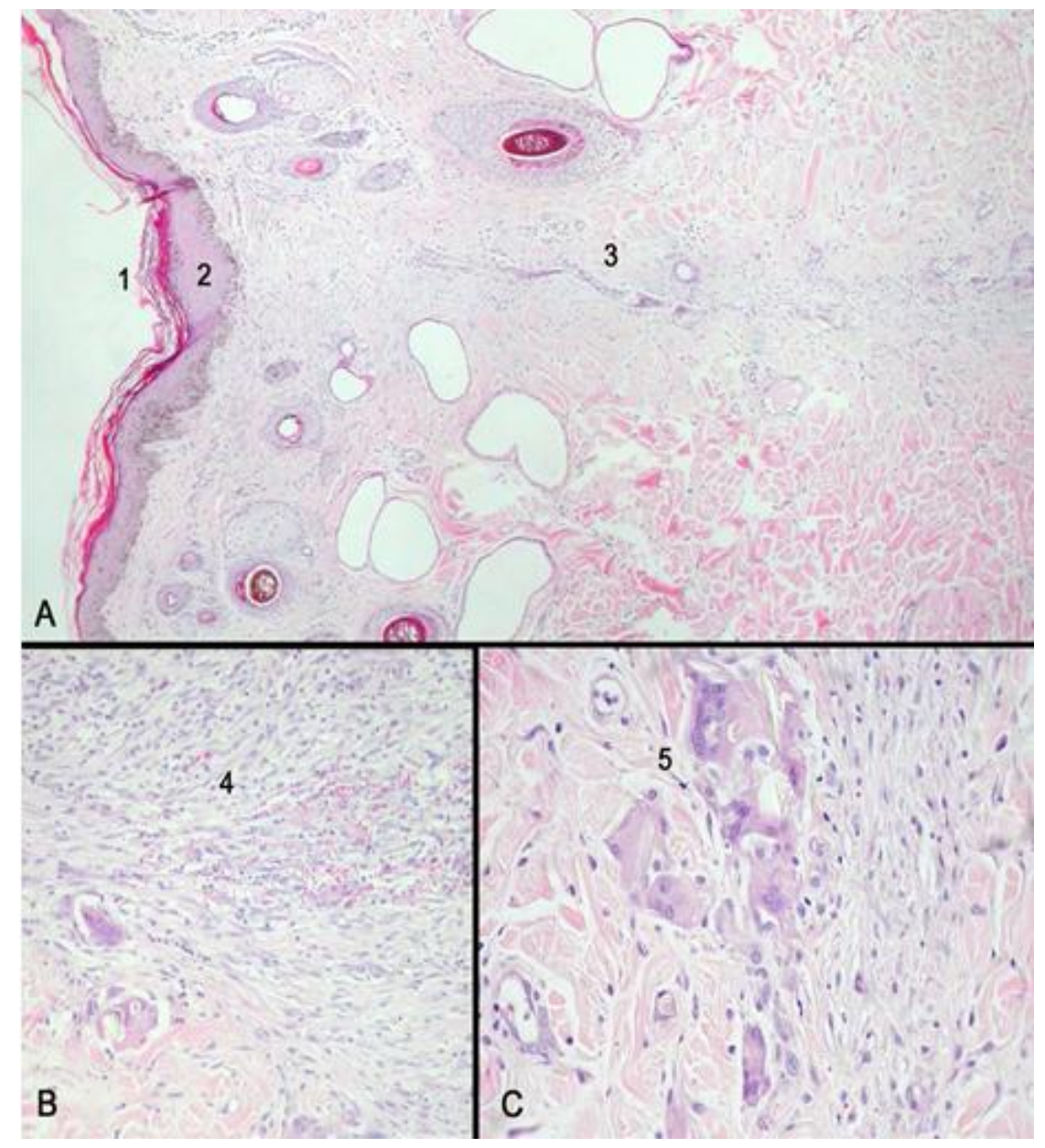

Figura 4 - Fotomicrografia de corte histológico de fragmento de pele de ovino submetido à dermorrafia com adesivo de etil-cianoacrilato (GC) no $10^{\circ}$ dia pós-operatório. A. retração da epiderme (1), Espessamento da epiderme (2), Inflamação (presença de neutrófilos) (3). B. Proliferação de fibroblastos na região da derme superficial (fibrose) (4). C. Célula gigante multinucleada fagocitando material birrefrigente (5). A (HE - 4X). B (HE - 20X). C (HE - 40X). 
Em ambos os grupos, em todos os animais que apresentaram reação inflamatória moderada (2) a acentuada (3) observou-se a presença de células gigantes multinucleadas fagocitando material birrefringente (Figura 4). No $10^{\circ}$ dia do pós-operatório, a inflamação foi significativamente maior no grupo tratamento que no grupo controle, não confirmando os resultados obtidos por Caldas e Gusmão (1998), que não mencionaram reação inflamatória quando usaram o adesivo de etilcianoacrilato na mucosa gengival de camundongos. Isso pode estar relacionado aos tipos de tecidos que foram suturados, uma vez que a pele reage de modo mais intenso à agressão cirúrgica. De qualquer forma, aos 20 e 30 dias pós-cirúrgicos já não foram detectadas diferenças entre os grupos, e os valores referentes ao grupo tratamento, nestes momentos, foram significativamente inferiores aos do $10^{\circ}$ dia.

Não foi observada nenhuma alteração macro e/ou microscópica que indicasse efeito tóxico do etilcianoacrilato, assim como relatado em caprinos (CORREIA, 2005), bovinos (COSTA, 2009) e asininos (MARQUES et al., 2013). Este fato possivelmente está relacionado à forma de aplicação do adesivo, que se restringiu às bordas da ferida, com a aplicação de pequena quantidade e de forma descontínua, conforme recomendado por Gottlob et al. (1980). Segundo Binnie e Forrest (1974) a aplicação do cianoacrilato dentro da ferida impede a epitelização da mesma, e Gottlob et al. (1980) citam que a aplicação de uma camada contínua bloqueia o trajeto para o crescimento de vasos, fato não ocorrido no presente experimento. A aplicação de uma pequena quantidade do adesivo é justificada por Elmasalme et al. (1995), os quais afirmam que o uso excessivo pode resultar em dano térmico aos tecidos circundantes.

Conclui-se que, em ovinos, o adesivo de etilcianoacrilato possui boa adesividade e o seu emprego na síntese cutânea reduz o tempo de duração do procedimento cirúrgico e propicia melhor resultado estético quando comparado com dermorrafias realizadas de forma convencional, além de não interferir no processo cicatricial. Sendo assim, apresenta-se como uma opção para a realização de dermorrafias nesta espécie, sobretudo em situações em que há a necessidade de redução do tempo operatório.

\section{REFERÊNCIAS}

ANDRADE, J. N. B. M.; CUEVAS, S. E.; MANISCALCO, C. L.; STEFANES, S. A.; JUNQUEIRA, J.; SANTOS, P. P. Uso do etil-cianoacrilato na síntese da parede vascular em cães. Ars Veterinária, v.17, n.3, p.172176, 2001.

BAPTISTA, R. R. C. Los cianoacrilatos en cirugia. Revista de Sanidad Militar, v.59, n.1, p.55- 58, 1995.

BINNIE, W. H.; FORREST, J. O. A study of tissue response to cyanoacrylate adhesive in periodontal surgery. Journal of Periodontology, v.45, p.619, 1974.

BORBA, C. C. ; NETO, E. R. ; VAL, L. R. L. ; BORBA JR, C. A.; SOUFEN, M. A. ; NETO, A. F. ; SAKOTANI,
A. Y. Uso do cianoacrilato na síntese da pele de ratos: trabalho de pesquisa experimental. Acta Cirúrgica Brasileira, v.15, n.1, p.48-54, 2000.

CALDAS JR, A. F.; GUSMÃO, E. S. Estudo clínico comparativo da coaptação dos tecidos gengivais, após cirurgia a retalho, utilizando-se etil-cianoacrilato (superbonder) e fio de sutura. Periodontia, v.7, n.1, p.35-42, jan./abr., 1998.

COSTA, J. M. T. Avaliação cicatricial de feridas cutâneas experimentais suturadas com cola de cianoacrilato (Superbonder), em bovinos. 2009. $24 \mathrm{f}$. Monografia (Graduação em Medicina Veterinária). Curso de Medicina Veterinária - Centro de Saúde e Tecnologia Rural, Universidade Federal de Campina Grande, Patos.

CORREIA, A. P. Avaliação da cola cianoacrilato na síntese de feridas cutâneas de caprinos. 2005. 36 f. Monografia (Graduação em Medicina Veterinária). Curso de Medicina Veterinária - Centro de Saúde e Tecnologia Rural, Universidade Federal de Campina Grande, Patos.

DE MELO, W. M.; MAXIMIANO, W. M.; ANTUNES, A. A.; BELOTI, M. M.; ROSA, A. L.; DE OLIVEIRA, P. T. Cytotoxicity testing of methyl and ethyl 2cyanoacrylate using direct contact assay on osteoblast cell cultures. Journal of Oral and Maxillofacial Surgery, v. 71, n.1, p. 35-41, 2013.

EDWAB, R. R. Choosing suture materials and needles. Dent Econ, p. 78-79, Aug. 1995.

ELMASALME, F. N.; MATBOULI, S. A.; ZUBERI, M. S. Use of tissue adhesive in the cloruse of small incisions and lacerations. Journal of Pediatric Surgery, v.30, n.6, p.837-838, 1995.

FEITOSA, F. L. F. Exame físico geral ou de rotina. In: Semiologia Veterinária: a arte do diagnóstico. São Paulo: Roca, 2004, cap.4, p.77-102.

FISCH, R. A. An adhesive for primary closure of skin incisions. Plastic and Reconstructive Surgery, v.30, p.607-10, 1962.

FOSSUM, T. W. Cirurgia do Sistema Tegumentar In: Cirurgia de Pequenos Animais. 1.ed. São Paulo: Roca, 2002, p.101 - 117.

GOTTLOB, R.; ZINNER, G.; DONAS, P.; LECHNER, G. grid adhesion: a new type of tissue union. International Surgery, v.65, n.2, p.139-149, 1980.

HACHIDA, M.; NARUNS, P.; MORRIS, S.; IRIE, I.; COCHRAN, A. J.; MORTON, D. L. Bronchial anastomosis with a tissue adhesive. Journal Thoracic and Cardiovascular Surgery, v.93, n.3, p.344-349, 1997.

HESS, C. T. Tratamento de feridas e úlceras. $4^{\mathrm{a}} \mathrm{ed}$. Rio de Janeiro: Reichmann e Affonso, 2002. p.1-57. 
KIM, S.; EVANS, K.; BISWAS, A. Production of BSA-poly (ethyl cyanoacrylate) nanoparticles as a coating material that improves wetting property. Colloids Surfaces B Biointerfaces, v.107, n.1, p.6875, 2013.

MAIA, C. C.; FILHO, M. C.; ABRAHÃO, S.; SILVA, J. C. C. B.; GOMES, P. A.; SOUFEN, M. A.; NOVO, N. F.; JULIANO, Y. Efeitos do etil-cianoacrilato na parede venosa de cães. Acta Cirúrgica Brasileira, v.17, n.1, p.55-61, 2002.

MARQUES, D. D.; NÓBREGA NETO, P. I., CARVALHO, K. S. Emprego da cola de cianoacrilato em feridas cutâneas de asininos. Ciência Animal Brasileira, v.14, n.1, p.74-80, 2013.

MATERA, J. M;, BRASS, W.; MESSOW, C. Estudo experimental sobre o uso de cianoacrilatos para anastomose intestinal látero-lateral em cães. Acta Cirúrgica Brasileira, v. 14, n.1, 1999.

MIXTER, R. C. Endoscopic forehead fixation with histoacryl [letter]. Plastic and Reconstructive Sugery, v.101, n.7, p.2006-2007, 1998.

OLIVEIRA G. P. Dinâmica parasitária de bernes em bovinos. I. Incidência em relação ao decúbito. Pesquisa Agropecuária Brasileira, v.26, p.467-71, 1991.

PAPATHEOFANIS, F. J.; BARMADA, R. The principles and applications of surgical adhesives. Surgery Annual, v.25, n.1, p.49-81, 1993.
REECE, T. B., et al. A prospectus on tissue adhesives. The American Journal of Surgery, v.182, p.40-44, 2001.

SASKA, S.; ROSLINDO, E. B.; ANDRÉ, P. D.; MINARELLI-GASPER, A. M. Uso do adesivo à base de etil - cianoacrilato na reparação óssea. Revista Brasileira de Ortopedia, v.56, n.3, p.461-467, 2004.

SHERMAK, M. A.; WONG, L.; INOUE, N.; CRAIN, B. J.; IM, M. J.; CHAO, E. Y.; MANSON, P. N. Fixation of the craniofacial skeleton with butyl-2cyanoacrylate and its effect on histotoxicity and healing. Plastic and Reconstructive Surgery, v.102, p.309-318, 1998 .

VASTANI, A.; MARIA, A. Healing of intraoral wounds closed using silk sutures and isoamyl 2cyanoacrylate glue: a comparative clinical and histologic study. Journal of Oral and Maxillofacial Surgery, v.71, n.2. p. 241-8, 2013

WATTÉ, C. M.; ELKS, R.; MOORE, D. L.; MCLELLAN, G. J. Clinical experience with butyl-2cyanoacrylate adhesive in the management of canine and feline corneal disease. Veterinary Ophthalmology, v.7, p.319-326, 2004. 